\title{
Sheehan's syndrome in Xinjiang: Clinical characteristics and laboratory evaluation of 97 patients
}

\author{
Guo-li Du, ${ }^{1, *}$ Zhong-hua Liu, ${ }^{2, *}$ Min Chen, ${ }^{3, *}$ Rui Ma, ${ }^{1}$ Sheng Jiang, ${ }^{1}$ \\ Miriguli Shayiti, ${ }^{4}$ Jun Zhu, ${ }^{1}$ Aibibai Yusufu ${ }^{1}$
}

\begin{abstract}
${ }^{1}$ Department of Endocrinology, First Affiliated Hospital of Xinjiang Medical University, Urumqi; ${ }^{2}$ Department of Endocrinology, the Eastern Section of Linyi People's Hospital, Linyi; ${ }^{3}$ Department of Rehabilitation Medicine, People's Hospital of Xinjiang Uygur Autonomous Region, Urumqi; ${ }^{4}$ Department of MRI, First Affiliated Hospital of Xinjiang Medical University, Urumqi; China
\end{abstract}

*The authors have contributed equally to this paper

\begin{abstract}
OBJECTIVE: To evaluate the clinical and hormonal characteristics of patients with Sheehan's syndrome in Xinjiang, China. METHODS: 97 cases diagnosed as Sheehan's syndrome in our hospital from 1999 to 2013 were retrospectively reviewed. The medical history, physical examination findings and hormonal profiles were documented and analyzed. RESULTS: The mean age at diagnosis was $43.7 \pm 12.4$ years, with a mean diagnostic delay of $9.1 \pm 9.5$ years (range, 1 month-35 years). 10 of our patients $(10.3 \%)$ had a home birth. 96 of our patients $(99.0 \%)$ had a history of obstetric hemorrhage. The most common clinical presentation included amenorrhea $(80 / 97,82.5 \%)$, agalactia $(2 / 97,74.2 \%)$ and loss of axillary or pubic hair $(83 / 97,85.6 \%)$. Seventy two of our patients $(\mathbf{7 4 . 2 \%})$ failed to lactate and 80 of our patients $(82.5 \%)$ failed to resume menstruation. Hypothalamic dysfunction included the hypothalamic-pituitary-gonadal axis (HPG) (LH deficiency: 77/83 patients, 92.8\%; FSH deficiency: 73/83 patients, 88\%; E2 deficiency: 62 of 82 patients, 75.6\%), the hypothalamic-pituitary-thyroid (HPT) axis (TSH deficiency: 77/93 patients, $82.8 \%$, TT3 deficiency: $70 / 87$ patients, $80.5 \%$, TT4 deficiency: $72 / 87$ patients, 82.8\%) and the hypothalamus-pituitary-adrenal (HPA) axis (ACTH deficiency: 19/37 patients, 51.4\%, cortisol deficiency: $49 / 64,76.6 \%$ ). CONCLUSIONS: Sheehan's syndrome is still common in Xinjiang, especially in rural areas. Long diagnosis delay in most of the patients indicates that women might be lacking correct diagnosis and treatment. Physicians need to be aware of the most important clues for diagnosis such as lack of lactation in the postpartum period and failure to resume menstruation.
\end{abstract}

Key words: Diagnosis delay, Hypopituitarism, Postpartum hemorrhage, Sheehan's syndrome

Address for correspondence:

Aibibai Yusufu, MD, Department of Endocrinology, First Affiliated Hospital of Xinjiang Medical University, No. 137 Liyushan Road, Urumqi, Xinjiang, 830011, China; Tel.: +86 18599077558; Fax: +86 9914319117; E-mail: genemagic@126.com

Jun Zhu, MM, Department of Endocrinology, First Affiliated Hospital of Xinjiang Medical University, No. 137 Liyushan Road, Urumqi, Xinjiang, 830011, China; Tel.: +86 13899981212; Fax:+86 9914319117; E-mail: zhujun6677@163.com

Received: 24-04-2015, Accepted: 04-08-2015 


\section{INTRODUCTION}

Sheehan's syndrome (or post-partum pituitary necrosis) was first recorded and named by Dr. Harold Leeming Sheehan in 1937. It is thought to be caused by ischemic pituitary necrosis associated with massive uterine hemorrhage and/or shock at delivery. The exact pathogenesis of Sheehan's syndrome is not yet well understood. ${ }^{1-3}$

Sheehan's syndrome occurs as varying degrees of anterior pituitary dysfunction or panhypopituitarism. Failure to lactate or to resume menses is the most common presentation in patients of Sheehan's syndrome. Other frequent manifestations include characteristics of genital and axillary hair loss, reduced bone mineral density, signs of dry skin, pallor and other evidence of hyponatremia, diabetes insipidus and hypoglycemia. ${ }^{4-7}$

Because the classical signs of Sheehan's syndrome (agalactia, amenorrhea) are difficult to detect, making a correct diagnosis is not easy. However, given that the diagnostic delay of Sheehan's syndrome is reported to be from 1 month to as much as 33 years, ${ }^{8}$ it is obvious that efforts must be made to more promptly identify and treat affected patients so as to avoid this delay. In this research study, we retrospectively documented and evaluated 97 patients with Sheehan's syndrome over 15 years. The clinical manifestation and laboratory characteristic features of these patients are analyzed and critical indicators for accurate diagnosis of Sheehan's syndrome suggested.

\section{MATERIALS AND METHODS}

The First Affliated Hospital of Xinjiang Medical University is a large major medical center located in Urumuqi, the capital of the Xinjiang Uygur Autonomous Region in northwest China. In this study we evaluated 97 patients with Sheehan's syndrome diagnosed in the endocrinology department of our hospital between 1999 and 2013.

The diagnosis of Sheehan's syndrome was based on patient history (profound bleeding during or following delivery, absence of postnatal lactation, etc.), physical examination, laboratory investigations and radiological and MRI evaluation of the pituitary.

The medical history of the patient included the regularity of lactation during the postpartum period, menstrual cycles after the postpartum period, number of pregnancies, last delivery at home or in hospital, history of stillbirth and abortion, hemorrhage during and/or after delivery, history of blood transfusion and other symptoms of hypopituitarism including adrenal failure and hypothyroidism. Information on lactation was based solely on statements made by the women since it was not possible to test lactation by an objective measure.

To diagnose Sheehan's syndrome, details of the physical examination were assessed, including breast atrophy, loss of axillary or pubic hair and myxedema. Laboratory investigations were also analyzed, such as pituitary hormone levels, complete blood cell count and biochemical parameters (including glucose, sodium and potassium).

All basal hormones were assessed in the central laboratory of our hospital. TSH, T3 and T4 levels were assessed using Roche assays (Cobas 8000, Germany). FSH, LH, GH and cortisol levels were assessed using a Beckman Dx1800 analyzer (USA) with the microparticle enzyme immunoassay technique.

\section{STATISTICAL ANALYSIS}

Statistical analysis was performed using SPSS 17.0. Most of the variables were analyzed through descriptive statistics (such as average, percentage and interquartile ranges). Results are presented as means \pm SD for the quantitative variables.

\section{RESULTS}

Mean age of the patients was $43.7 \pm 12.4$ years (range 22-69 years); clinical features and characteristics of the 97 patients are given in Table 1. The mean duration between the last obstetric event and diagnosis was $9.1 \pm 9.5$ years (range, 1 month-35 years). Ten $(10.3 \%)$ had a history of home birth and 15 (15.5\%) had a history of cesarean delivery. One (1\%) patient had had a spontaneous abortion and $1(1 \%)$ patient had had a drug abortion. Ninety-six (99\%) had a history of hemorrhage, while a positive history of low arterial pressure was elicited from 46 patients (47.4\%). Eighty-seven (90\%) patients who delivered at hospital had been given blood or fluid replacement and 54 $(55.7 \%)$ had a history of blood transfusion. Eighty 
Table 1. Clinical presentation and physical examination of patients with Sheehan's syndrome

\begin{tabular}{lc}
\hline $\begin{array}{l}\text { Clinical presentation } \\
\text { and physical examination }\end{array}$ & $\begin{array}{c}\text { Mean } \pm \text { SD or } \\
\text { n (\%) }\end{array}$ \\
\hline Systolic BP $(\mathrm{mmHg})$ & $104 \pm 19$ \\
Diastolic BP $(\mathrm{mmHg})$ & $69 \pm 16$ \\
Heart rate (beats $/ \mathrm{min})$ & $76 \pm 11$ \\
Respiratory rate $($ breaths $/ \mathrm{min})$ & $19 \pm 2$ \\
Axillary body temperature $\left({ }^{\circ} \mathrm{C}\right)$ & $36.4 \pm 0.6$ \\
Cold intolerance & $56(57.7)$ \\
Decreased or absent pubic & $83(85.6)$ \\
or axillary hair & \\
Slow reflexes & $32(33.0)$ \\
Cognitive changes & $8(8.2)$ \\
Pallor & $64(66.0)$ \\
Sparse hair and eyebrows & $79(81.4)$ \\
Dry skin & $68(70.1)$ \\
Myxedema & $27(27.8)$ \\
Hypopigmentation in the nipple-areola & $39(40.2)$ \\
Mammary gland atrophy & $9(9.3)$ \\
Vaginal atrophy & $12(12.4)$ \\
Low body weight $\left(\mathrm{BMI}<18.5 \mathrm{~kg} / \mathrm{m}^{2}\right)$ & $3(7)$ \\
Overweight $\left(\mathrm{BMI}, 25\right.$ to $\left.28 \mathrm{~kg} / \mathrm{m}^{2}\right)$ & $14(32.6)$ \\
Obese $\left(\mathrm{BMI} \geq 28 \mathrm{~kg} / \mathrm{m}^{2}\right)$ & $3(7)$ \\
\hline Values are & \\
\hline
\end{tabular}

Values are means \pm SD. BP: blood pressure; BMI: body mass index. For body weight summary, a total of 43 patients data had been collected.

$(82.5 \%)$ presented failure to resume menstruation. Seventeen (17.5\%) had no history of menopause, but did present shortened menstrual bleeding or irregular uterine bleeding. Four $(4.1 \%)$ had a history of peripartum hysterectomy. The causes of obstetric events include placental retention $(2 / 97,2.1 \%)$ and multiple pregnancy $(3 / 97,3.1 \%)$. No data about other causes of hemorrhage are available.

Of the 97 patients of the study, 72 (74.2\%) presented with loss of lactation, 75 (77.3\%) had symptoms of lethargy and $56(57.7 \%)$ had symptoms of intolerance to cold. Loss of axillary or pubic hair was found in 83 patients (85.6\%). Dry skin was recorded in $68(70.1 \%)$ patients and pallor in $64(66.0 \%)$ patients. Signs of myxedema were found in 27 patients $(27.8 \%)$.

For blood pressure (BP), only 94 patients' materials had been collected. Mean systolic BP was
$104 \pm 19 \mathrm{mmHg}$ (range, 50 to $160 \mathrm{mmHg}$ ) and mean diastolic BP was $69 \pm 16 \mathrm{mmHg}$ (range, 30 to 110 $\mathrm{mmHg}$ ). $19.15 \%$ had hypotension (18/94, with systolic BP less than $90 \mathrm{mmHg}$ or/and diastolic BP less than $60 \mathrm{mmHg}$ ). Mean heart rate was $76 \pm 11$ beats $/ \mathrm{min}$ (range, $56-125$ beats $/ \mathrm{min}$ ) and mean respiratory rate was $19 \pm 2$ breaths/min (range, 10-23 breaths/min). The mean axillary body temperature was $36.4 \pm 0.6$ ${ }^{\circ} \mathrm{C}$. Five $(5.3 \%)$ had an axillary temperature higher than $37.3^{\circ}$. For body temperature, only 94 patients' materials had been collected, $5(5.3 \%)$ had an axillary temperature higher than $37.3^{\circ} \mathrm{C}, 81(86.2 \%)$ were $36.0^{\circ} \mathrm{C}$ to $37.3^{\circ} \mathrm{C}$ and $8(8.5 \%)$ were lower than $36.0^{\circ} \mathrm{C}$ (Table 1$)$.

In this study, $32.6 \%$ were overweight (14/43, BMI, 25 to $28 \mathrm{~kg} / \mathrm{m}^{2}$ for Chinese), $6.9 \%$ were obese (3/43, BMI $\geq 28 \mathrm{~kg} / \mathrm{m}^{2}$ for Chinese), $53.5 \%$ were normal (23/43, BMI, 18.5 to $25 \mathrm{~kg} / \mathrm{m}^{2}$ for Chinese) and $7.0 \%$ had low body weight $(23 / 43$, BMI $<18.5$ $\mathrm{kg} / \mathrm{m}^{2}$ for Chinese). Mean hemoglobin concentration was $107.6 \pm 17.7 \mathrm{~g} / \mathrm{L}$ (data of 90 patients available, range, $56-142.4 \mathrm{~g} / \mathrm{L})$. Sixty-seven (74.44\%) had anemia (hemoglobin concentration $<120 \mathrm{~g} / \mathrm{L}$ ). Average lymphocyte count: neutrophil ratio was $37.0 \pm 15.6 \%$ (data available for 90 patients, range, 3.3\%-84.4\%) and $41(45.6 \%)$ were higher than $40 \%$. Mean erythrocyte sedimentation rate (ESR) was $29 \pm 21 \mathrm{~mm} / \mathrm{h}$ and 14 $(56.0 \%)$ were higher than $20 \mathrm{~mm} / \mathrm{h}$.

In our study, mean sodium was $135.7 \pm 8.7 \mathrm{mmol} / \mathrm{L}$ and 31 (33.7\%, range, $106-159.2 \mathrm{mmol} / \mathrm{L}, 92$ patients analyzed) had hyponatremia. Average fasting glucose was $4.8 \pm 1.8 \mathrm{mmol} / \mathrm{L}$ (data available for a total of 87 patients) and 23 (26.4\%) had hypoglycemia (less than $3.9 \mathrm{mmol} / \mathrm{L}$ ). Mean triglyceride concentration was $2.3 \pm 2.0 \mathrm{mmol} / \mathrm{L}$ (range, $0.37-13.37 \mathrm{mmol} / \mathrm{L}$, data available for a total of 81 patients) and $39(48.1 \%)$ were higher than $1.7 \mathrm{mmol} / \mathrm{L}$. Mean cholesterol concentration was $5.23 \pm 1.59 \mathrm{mmol} / \mathrm{L}$ (range, 2.30$9.98 \mathrm{mmol} / \mathrm{L})$ and $28(34.6 \%)$ were higher than 5.72 $\mathrm{mmol} / \mathrm{L}$ (Table 2).

Among the 87 patients who had their TT3 and TT4 checked, 72 patients showed TT4 and TSH deficiency, while overall no primary hypothyroidism was found. The other 5 patients with the clinical manifestation of hypothyroidism had only their TSH checked, but not TT3 and TT4: they showed TSH 
Table 2. General laboratory results of the patients with Sheehan's syndrome

\begin{tabular}{lccccc}
\hline & Data collected & Mean \pm SD & Normal range & n (\%) & Interval \\
\hline $\mathrm{Hb}(\mathrm{g} / \mathrm{L})$ & 90 & $107.6 \pm 17.7$ & $120-160$ & $67(74.4)$ & $56.0-119.5$ \\
$\mathrm{LNR}(\%)$ & 90 & $37.0 \pm 15.6$ & $20-40$ & $41(45.6)$ & $40.5-72.5$ \\
$\mathrm{ESR}(\mathrm{mm} / \mathrm{h})$ & 25 & $29 \pm 21$ & $0-20$ & $14(56.0)$ & $21-80$ \\
$\mathrm{Sodium}(\mathrm{mmol} / \mathrm{L})$ & 92 & $135.7 \pm 8.7$ & $135-155$ & $31(33.7)$ & $106.0-134.9$ \\
$\mathrm{FPG}(\mathrm{mmol} / \mathrm{L})$ & 87 & $4.8 \pm 1.8$ & $3.9-6.1$ & $23(26.4)$ & $1.0-3.87$ \\
$\mathrm{TG}(\mathrm{mmol} / \mathrm{L})$ & 81 & $2.3 \pm 2.0$ & $0.5-1.7$ & $39(48.1)$ & $1.76-7.55$ \\
$\mathrm{TC}(\mathrm{mmol} / \mathrm{L})$ & 81 & $5.23 \pm 1.59$ & $2.8-5.72$ & $28(34.6)$ & $5.73-9.98$ \\
\hline
\end{tabular}

Values are means \pm SD. Hb: Hemoglobin; LNR: lymphocyte to neutrophil ratio; ESR: erythrocyte sedimentation rate; FPG: fasting blood glucose; TG: triglyceride; TC: total cholesterol.

deficiency. Seventy patients $(80.5 \%$, data available for 87 patients) had insufficient total T3, 72 patients (82.8\%, data available for 87 patients) had insufficient total T4, 34 patients $(82.8 \%$, data available for 41 patients) had insufficient free $\mathrm{T} 3$ and 34 patients (90.2\%, data available for 41 patients) had insufficient free T4 (shown in Table 3). In total, 77 (82.8\%, data available for 93 patients) had clinical manifestations of hypothyroidism and TSH deficiency (mean TSH: $2.98 \pm 2.89 \mathrm{mU} / \mathrm{L}$ ), judged as having HPT axis. In regard to the HPA axis, $49(76.6 \%$, data available for 64 patients) had insufficient cortisol and $19(51.4 \%$, data available for 37 patients) had insufficient ACTH.

Regarding the HPG axis, 82 patients had their serum estradiol concentration checked. Sixty-two (75.6\%) patients had insufficient estradiol, FSH and

Table 3. Basal hormone levels of the patients with Sheehan's syndrome

\begin{tabular}{|c|c|c|c|c|c|c|}
\hline & $\mathbf{n}$ & Mean \pm SD & Range & $\begin{array}{c}\text { Interquartile } \\
\text { ranges }\end{array}$ & $\begin{array}{c}\text { Reference } \\
\text { range }\end{array}$ & $\begin{array}{l}\text { Hormonal } \\
\text { deficiency }\end{array}$ \\
\hline PRL (ng/ml) & 82 & $5.02 \pm 16.32$ & $0.11-12.94$ & $0.95-3.66$ & $3.4-24.1$ & $47(57.3 \%)$ \\
\hline Progesterone (ng/ml) & 78 & $2.0 \pm 2.2$ & $0-10.7$ & $0.4-2.9$ & $1.7-27$ & $52(66.7 \%)$ \\
\hline FSH (mIU/ml) & 83 & $6.17 \pm 4.9$ & $0.21-29.5$ & $2.8-7.93$ & $16.74-113.59$ & $73(88.0 \%)$ \\
\hline Testosterone (ng/ml) & 61 & $0.06 \pm 0.06$ & $0-0.33$ & $0.01-0.10$ & $<0.1-0.75$ & $41(67.2 \%)$ \\
\hline LH (mIu/ml) & 83 & $0.25 \pm 0.34$ & $0.1-11$ & $0.11-0.65$ & $1.0-11.4$ & $77(92.8 \%)$ \\
\hline Estradiol (pg/ml) & 82 & $15.27 \pm 20.42$ & $0-144$ & $5.0-38.4$ & $40.0-261$ & $62(75.6 \%)$ \\
\hline ACTH (ng/ml) & 37 & $7.95 \pm 6.51$ & $1-25.59$ & $3.49-10.79$ & $5-60$ & $19(51.4 \%)$ \\
\hline Cortisol (local time: 8AM, ug/dl) & 64 & $3.24 \pm 2.78$ & $0-20.85$ & $1.32-6.15$ & $6.7-22.6$ & $49(76.6 \%)$ \\
\hline TT3 (ng/ml) & 87 & $0.62 \pm 0.42$ & $0.2-1.7$ & $0.21-0.71$ & $0.80-2.0$ & $70(80.5 \%)$ \\
\hline TT4 (ug/dl) & 87 & $3.76 \pm 2.75$ & $0.1-10.47$ & $1.84-4.3$ & $5.1-14.1$ & $72(82.8 \%)$ \\
\hline FT3 (pg/ml) & 41 & $2.02 \pm 1.75$ & $0.26-4.3$ & $1.3-1.89$ & $2-4.4$ & $34(82.9 \%)$ \\
\hline FT4 (ng/dl) & 41 & $0.88 \pm 0.94$ & $0.06-1.56$ & $0.58-0.90$ & $0.93-1.7$ & $37(90.2 \%)$ \\
\hline TSH (mU/l) & 93 & $0.30 \pm 0.29$ & $0.01-4.1$ & $0.01-0.24$ & $0.27-4.2$ & $77(82.8 \%)$ \\
\hline GH (ng/ml) & 25 & $0.41 \pm 0.51$ & $0.01-1.58$ & $0.05-0.58$ & $0-10$ & $\begin{array}{c}\text { No data of } \\
\text { stimulation test }\end{array}$ \\
\hline \multirow[t]{2}{*}{ IGF-1 (ng/ml) } & 3 & $<25$ & $<25$ & $\mathrm{~N}$ & 10-20ys : $88-996$ & $3(100.0 \%)$ \\
\hline & & & & & 21-85ys : 55-166 & \\
\hline \multirow[t]{2}{*}{ IGFBP-3 (ug/ml) } & 3 & $0.59 \pm 0.09$ & $0.50-0.67$ & $\mathrm{~N}$ & $10-20 y s: 2.1-10$ & $3(100.0 \%)$ \\
\hline & & & & & $21-85 y s: 2.2-7.8$ & \\
\hline
\end{tabular}

Values are means \pm SD. PRL: prolactin; FSH: follicle stimulating hormone; LH: Luteinizing hormone; ACTH: corticotrophin; TT3: total triiodothyronine; TT4: total thyroxine; FT3: free triiodothyronine; FT4: free thyroxine; TSH: thyrotrophin; GH: growth hormone; IGF: insulin-like growth factor: IGFBP: insulin like growth factor binding protein. 
LH. Eleven patients with the clinical manifestation of hypogonadism whose estradiol concentration was at the lower limit of the normal range had insufficient FSH and LH. The other 3 patients whose estradiol and FSH concentration were at the lower limit of the normal range, with the clinical manifestation of hypogonadism, had insufficient LH. One patient with the clinical manifestation of hypogonadism and who had only LH and FSH checked but not estradiol showed insufficient LH and FSH levels at the lower limit of the normal range. In total, 77 (88.0\%, data available for 83 patients) patients with clinical manifestations of hypogonadism and FSH or/and LH deficiency were judged as having HPG dysfunction.

The serum prolactin concentrations of 47 (57.3\%, data available for 82 patients) were lower than the reference value. All of the 25 patients evaluated had insufficient basal GH. IGF-1 and IGFBP-3 were assessed in 3 patients and all of them had insufficient IGF-1 and IGFBP-3 (Table 3).

In this study, diagnoses of all patients with SS were confirmed via pituitary gland examination by magnetic resonance imaging (MRI); however, only 27 patients' pituitary MRI findings were collected. Twenty (74.1\%) had obvious pituitary involution, manifesting as empty sella or partial empty sella (Figure, total empty sella: A-E; partial empty sella: F-J). Two (7.4\%) had slight pituitary involution and 5 $(18.5 \%)$ had no obvious pituitary involution. Eighteen patients (age 22-47 years) had ultrasonic evaluation of uterine involution, $15(83.3 \%)$ had obvious uterine involution and $3(16.67 \%)$ had a normal-sized uterus.

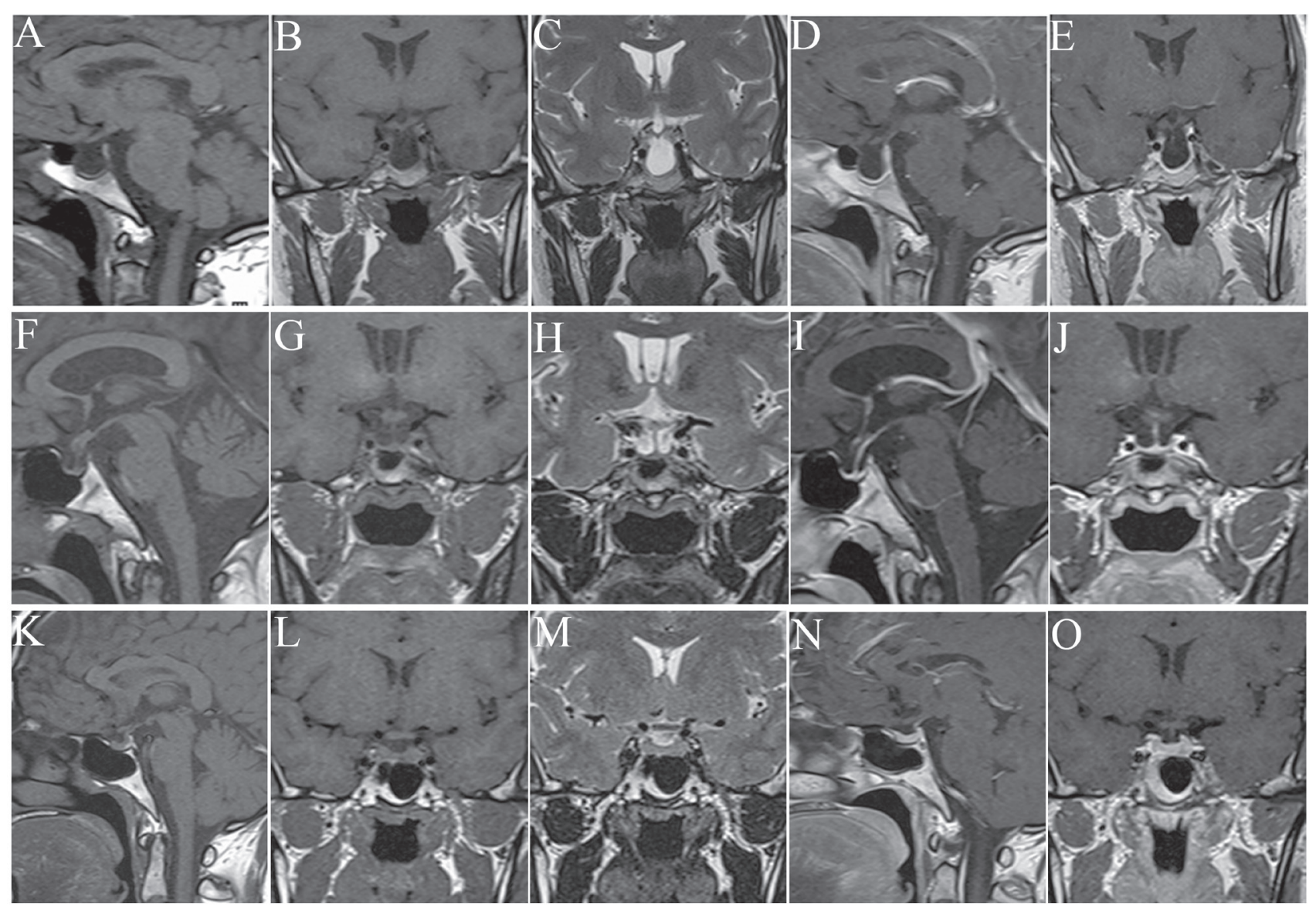

Figure. Magnetic resonance images scan of pituitaries of Sheehan's syndrome. A characteristic finding of Sheehan's syndrome is partial (A-E) or total (F-J) empty sella (T1-weighted images: A, B, F, G; T2-weighted images: C, H; sagittal T1 weighted-gadoliniumenhanced: D, I; coronal T1 weighted-gadolinium-enhanced: E, J). Slight pituitary involution is also presented in another patient of Sheehan's syndrome (T1-weighted images: K, L; T2-weighted image: M; sagittal T1 weighted-gadolinium-enhanced: N; coronal T1 weighted-gadolinium-enhanced: $\mathrm{O})$. 
Only one patient was scanned with adrenal computed tomography (CT) and she had bilateral adrenal atrophy.

A total of $85(87.6 \%)$ were prescribed hormones to correct endocrine abnormalities. There was no available data for 12 patients (12.4\%). Eighty-four ( $98.8 \%$, data available for 85 patients) were prescribed steroids and 78 (91.8\%, data available for a total of 85 patients) were prescribed thyroxine. Thirty-two (37.6\%, data available for 85 patients) patients were prescribed estrogen.

\section{DISCUSSION}

In developing countries, and especially in the rural areas, Sheehan's syndrome is the most common cause of hypopituitarism. ${ }^{9}$ The diagnosis of Sheehan's syndrome is often delayed. However, identification of affected patients is critical since avoidance of diagnosis delays of Sheehan's syndrome reduces morbidity and mortality. The medical history of the patient, clinical manifestations, detection of low levels of pituitary target gland hormones and MRI scan of the pituitary are important aids to the diagnosis of Sheehan's syndrome. ${ }^{4,7,10-12}$

The clinical manifestations include non-specific complaints such as asthenia, weakness and fatigue, signs of loss of axillary or pubic hair, dry skin, hypopigmentation, hypotension, hypoglycemia and other hypopituitarism symptoms. ${ }^{13-17}$

In our study, the diagnosis delay of Sheehan's syndrome was 1 month to 35 years and the mean duration was $9.1 \pm 9.5$ years. We found that massive bleeding at delivery, failure to resume menstruation, agalactia and signs of axillary or pubic hair loss were very important clues for identification of Sheehan's syndrome. Ninety-nine percent $(99 \%)$ of the patients were found to have had massive bleeding at delivery, $82.5 \%$ patients were found to have failed to resume menstruation, $74.2 \%$ patients presented agalactia and $85.6 \%$ had loss of axillary or pubic hair.

Of the 97 patients, this being consistent with previous reports, most $(72,74.2 \%$, prolactin range: $0.11-2.65 \mathrm{ng} / \mathrm{mL}$ ) presented with loss of lactation. It is noteworthy that $25.8 \%$ of the women in our series were reportedly able to lactate (prolactin range: 3.43 $12.94 \mathrm{ng} / \mathrm{mL}$ ), a proportion considerably higher than the usually reported $0 \%$ to $7 \%$. In another study, GeiGuardia et al showed that the proportion of lactation in patients of Sheehan's syndrome did not surpass $33 \% .{ }^{18}$ These different percentages of endocrine abnormalities documented in recently published series could be attributed to non-homogenous impairment of anterior pituitary functions.

The mean BMI was $24.4 \pm 5.9 \mathrm{~kg} / \mathrm{m}^{2}$, consistent with that reported by Deniz Gokalp (mean BMI: $22.9+2.6$ to $24.2+4.1 \mathrm{~kg} / \mathrm{m}^{2}$ ). Regarding body weight analysis, the limitation of this study was that data were available for only $43(39.5 \%)$ patients and, further, a larger sample size being needed to confirm our results.

The general laboratory findings in our study, such as hyponatremia, hypoglycemia, anemia and relative lymphocytosis, were consistent with previous reports. ${ }^{19-25}$

One patient in our study had overt central diabetes insipidus (DI): her polyuria had lasted for 5 months after delivery. $24 \mathrm{~h}$ urinalysis after $12 \mathrm{~h}$ fluid restriction confirmed a urine density of 1.000 with simultaneous plasma sodium $159 \mathrm{mmol} / \mathrm{L}$ and osmolality $335 \mathrm{mOsm} / \mathrm{kg}$. There were no significant changes in other serum laboratory tests including plasma urea, creatinine, potassium and calcium levels. No cases of central diabetes insipidus have been reported in most published case series. Atmaca et al, ${ }^{26}$ however, found subtle necrosis within the posterior lobe in many patients with Sheehan's syndrome, the osmotic threshold for the onset of thirst was increased due to the thirst centre affected by ischemic damage and $29 \%$ of patients had partial central DI. This led us to identify posterior pituitary deficiency compatible with Sheehan's syndrome in a few rare cases..$^{27,28}$

Alterations in endocrine systems were analyzed and the most commonly affected endocrine system was the HPG axis $(88.0 \%$ had decreased FSH and $92.8 \%$ had decreased LH), followed by the HPT axis (82.8\% patients affected) and the HPA axis $(76.6 \%$ patients affected).

In women, testosterone is thought to influence pubertal development and sexual function. Since Sheehan's syndrome is one cause of testosterone deficiency, it is important to check for testosterone deficiency in women with Sheehan's syndrome for 
potential initiation of testosterone replacement therapy. In this study, 41 patients ( $67.2 \%$, data available for 61 patients) showed low concentrations of testosterone (Table 3).

Xinjiang is located in the northwest of China. Because of the low socioeconomic status of the population of this region, most of our patients have limited ability to afford medical care and treatment, while little or no data of growth hormone tests and dynamic pituitary function tests are available to physicians. Therefore, it is essential that physicians in this region make efforts to correctly identify affected patients while placing more emphasis on dynamic pituitary function tests and growth hormone tests. One important outcome of Sheehan's syndrome is adrenal axis dysfunction, which can cause a lifethreatening crisis and often requires emergency treatment. According to a previous report, the diagnosis delay of those requiring emergency treatment was more likely to be shortened. ${ }^{12}$ In our study, $76.6 \%$ patients had HPA axis dysfunction, $26.4 \%$ had hypoglycemia and $33.7 \%$ had hyponatremia. Physicians must be aware of these manifestations to avoid increased mortality.

Xinjiang is located in the northwest of China and its population is composed of a number of different ethnic groups. The low socioeconomic status of our patients in this region may contribute to the diagnostic delay of Sheehan's syndrome. ${ }^{29}$ Again because of the low socioeconomic status of the different ethnic groups in this region, home deliveries are sometimes practiced, while obstetric assistance is poor, these factors possibly contributing to the diagnosis delay of Sheehan's syndrome. In our study, $10.3 \%$ of patients had a history of home birth and the mean diagnosis delay of Sheehan's syndrome was $9.1 \pm 9.5$ years. In one previous report, $22 \%$ patients had a history of home birth and the mean diagnosis delay of Sheehan's syndrome was 13 years. $^{7}$

In conclusion, in order to avoid delays in diagnosis and treatment of Sheehan's syndrome and to improve the quality of life of affected patients, greater awareness of this disorder must be encouraged among physicians and the general population. Characteristics such as history of severe postpartum hemorrhage, failure to resume menstruation, agalactia, signs of axillary or pubic hair loss and a trend to overt hypoglycemia and hyponatremia are critical clues to the early diagnosis of Sheehan's syndrome. Basal hormone tests are recommended to determine the affected axis before appropriate replacement therapy can be prescribed.

\section{ACKNOWLEDGEMENT}

We thank Professor Ablikm of the Department of Endocrinology, First Affiliated Hospital of Xinjiang Medical University, for his extremely useful advice concerning the writing of this article.

\section{FINANCIAL DISCLOSURES}

Nothing to declare.

\section{REFERENCES}

1. Bunch TJ, Dunn WF, Basu A, Gosman RI, 2002 Hyponatremia and hypoglycemia in acute Sheehan's syndrome. Gynecol Endocrinol 16: 419-423.

2. Goswami R, Kochupillai N, Crock PA, Jaleel A, Gupta N, 2002 Pituitary autoimmunity in patients with Sheehan's syndrome. J Clin Endocrinol Metab 87: 4137-4141.

3. Wilson V, Mallipedhi A, Stephens JW, Redfern RM, Price DE, 2014 The causes of hypopituitarism in the absence of abnormal pituitary imaging. QJM 107: 21-24.

4. Dokmetas HS, Kilicli F, Korkmaz S, Yonem O, 2006 Characteristic features of 20 patients with Sheehan's syndrome. Gynecol Endocrinol 22: 279-283.

5. Anfuso S, Patrelli TS, Soncini E, Chiodera P, Fadda GM, Nardelli GB, 2009 A case report of Sheehan's syndrome with acute onset, hyponatremia and severe anemia. Acta Biomed 80: 73-76.

6. Gokalp D, Tuzcu A, Bahceci M, Arikan S, Ozmen CA, Cil T, 2009 Sheehan's syndrome and its impact on bone mineral density. Gynecol Endocrinol 25: 344-349.

7. Gei-Guardia O, Soto-Herrera E, Gei-Brealey A, Chen$\mathrm{Ku} \mathrm{CH}, 2011$ Sheehan syndrome in Costa Rica: clinical experience with 60 cases. Endocr Pract 17: 337-344.

8. Huang YY, Ting MK, Hsu BR, Tsai JS, 2000 Demonstration of reserved anterior pituitary function among patients with amenorrhea after postpartum hemorrhage. Gynecol Endocrinol 14: 99-104.

9. Sheehan HL, 1965 The frequency of post-partum hypopituitarism. J Obstet Gynaecol Br Commonw 72: 103-111.

10. Ozbey N, Inanc S, Aral F, et al, 1994 Clinical and laboratory evaluation of 40 patients with Sheehan's syndrome. Isr J Med Sci 30: 826-829.

11. Ozkan Y, Colak R, 2005 Sheehan syndrome: clinical and laboratory evaluation of 20 cases. Neuro Endocrinol 
lett 26: 257-260.

12. Kristjansdottir HL, Bodvarsdottir SP, Sigurjonsdottir HA, 2011 Sheehan's syndrome in modern times: a nationwide retrospective study in Iceland. Eur J Endocrinol 164: 349-354.

13. Moodley KK, Broad R, Chung K, Riordan-Eva P, Sibtain NA, Moran NF, 2013 Sheehan syndrome associated with raised intracranial pressure. J Neuroophthalmol 33: 54-57.

14. Wang SY, Hsu SR, Su SL, Tu ST, 2005 Sheehan's syndrome presenting with early postpartum congestive heart failure. J Chin Med Assoc 68: 386-391.

15. Laway BA, Bhat JR, Mir SA, Khan RS, Lone MI, Zargar AH, 2010 Sheehan's syndrome with pancytopenia-complete recovery after hormone replacement (case series with review). Ann Hematol 89: 305-308.

16. Islam AK, Hasnat MA, Doza F, Jesmin H, 2014 Sheehan's syndrome with reversible dilated cardiomyopathy: A case report and brief overview. J Saudi Heart Assoc 26: $117-120$.

17. Greco DS, 2012 Pituitary deficiencies. Top Companion Anim Med 27: 2-7.

18. Shivaprasad C, 2011 Sheehan's syndrome: Newer advances. Indian J Endocrinol Metab 15: Suppl 3: 203-207.

19. Ascoli P, Cavagnini F, 2006 Hypopituitarism. Pituitary 9: 335-342.

20. Du X, Yuan Q, Yao Y, Li Z, Zhang H, 2014 Hypopituitarism and successful pregnancy. Int J Clin Exp Med 7: 4660-4665.

21. Laway BA, Mir SA, Bashir MI, Bhat JR, Samoon J, Zargar AH, 2011 Prevalence of hematological abnormalities in patients with Sheehan's syndrome: response to replacement of glucocorticoids and thyroxine. Pituitary 14: 39-43.

22. Laway BA, Mir SA, Zargar AH, 2013 Recovery of prolactin function following spontaneous pregnancy in a woman with Sheehan's syndrome. Indian J Endocrinol Metab 17: S696-699.

23. Dharmshaktu P, Bhowmick J, Manglani D, Dhanwal DK, 2013 Recurrent symptomatic hypoglycaemia with pancytopenia as a delayed presentation of Sheehan's syndrome with complete recovery after hormone replacement. BMJ Case Rep: doi:10.1136/bcr-2013009014

24. Banzal S, Ayoola EA, Banzal S, 1999 Sheehan's syndrome in Saudi Arabia. Int J Gynaecol Obstet 66: 181-182.

25. Sas AM, Meynaar IA, Laven JS, Bakker SL, Feelders RA, 2003 [Irreversible coma following hypoglycemia in Sheehan syndrome with adrenocortical insufficiency]. Ned Tijdschr Geneeskd 147: 1650-1653.

26. Atmaca H, Tanriverdi F, Gokce C, Unluhizarci K, Kelestimur F, 2007 Posterior pituitary function in Sheehan's syndrome. Eur J Endocrinol 156: 563-567.

27. Kan AK, Calligerous D, 1998 A case report of Sheehan syndrome presenting with diabetes insipidus. Aust $\mathrm{N}$ Z J Obstet Gynaecol 38: 224-226.

28. Merker E, Futterweit W, 1974 Postpartum amenorrhea, diabetes insipidus and galactorrhea. Report of a case and review of the literature. Am J Med 56: 554-558.

29. Abs R, Bengtsson BA, Hernberg-Stâhl E, et al, 1999 GH replacement in 1034 growth hormone deficient hypopituitary adults: demographic and clinical characteristics, dosing and safety. Clin Endocrinol (Oxf) 50: 703-713. 